ESJ Social Sciences

\title{
Mobile Payments, Demographics and Firm Performance in Kenya
}

\author{
Adrian Kamotho Njenga \\ Kenya Methodist University, Kenya \\ Kate Litondo \\ Germano Mwabu \\ University of Nairobi, Kenya
}

Doi:10.19044/esj.2021.v17n38p58

Submitted: 18 October 2021

Accepted: 21 November 2021

Published: 30 November 2021
Copyright 2021 Author(s)

Under Creative Commons BY-NC-ND

4.0 OPEN ACCESS

Cite As:

Njenga A.K., Litondo K. \& Mwabu G. (2021). Mobile Payments, Demographics and Firm Performance in Kenya. European Scientific Journal, ESJ, 17 (38), 58.

https://doi.org/10.19044/esj.2021.v17n38p58

\begin{abstract}
Technological advancements have presented firms with an opportunity to use mobile payments to enhance their performance. This study explores the relationship between mobile payments and firm performance in Kenya. The moderating effects of demographics are also studied. Using primary data collected from 289 supermarkets based in Nairobi City County, we determine whether the use of mobile payment has enhanced firm performance as defined by profitability, operation costs, revenues and the number of customers served. Empirical results from logit regression analysis reveal that the use of a mobile to make payments in supermarkets directly impacts the performance of supermarkets. Additionally, consumer characteristics have a significant moderating effect on the relationship between mobile payments and profitability of supermarkets. We conclude that the use of mobiles to make payments in supermarkets in Kenya has acquired the requisite critical mass level to be in a position to influence revenues of these firms.
\end{abstract}

Keywords: Demographics, Firm performance, Mobile payments 


\section{Introduction}

The advent of electronic commerce and mobile technologies has revolutionized the global payment landscape through digitalization. Regarded as the precursor to mobile payments, electronic commerce uses information and communication technologies based on telecommunication networks, cryptography, among other innovative integrations to enable payment service (Demombynes \& Thegeya, 2012). New opportunities for service and information provision, buying and selling of goods and instantaneous money exchange define the online perspective of doing business, leading to the immense popularity of mobile payment solutions.

In response to the Covid-19 pandemic governments have relaxed regulatory controls on mobile payments thereby intensifying utilization of digital payment platforms. For instance, the Kenyan government waived digital transfer fees and doubled the maximum limit for online transactions in the wake of the pandemic. Paradigm shifts in consumer behavior and buying preferences have evolved, with consumers and retailers switching to cashless transactions as the use of digital payments spread in the retail sector and other industries. Governments have also embraced digital solutions in service delivery and performance of public functions. (Bandura \& Ramanujam, 2021).

Payment options that ride on applications installed by mobile payment providers on consumers' mobile devices have gradually emerged. Further, contemporary innovations in mobile devices, hardware and communication technology present additional tools for doing business by offering platforms for new shopping methods (Okereke, 2017). By promising greater value to retailers and consumers, mobile payment services have challenged the status quo within the payment spectrum previously dominated by banks. Further, by enabling proximity transactions, mobile payments are rapidly becoming suitable alternatives to the traditional point of sale systems.

Efficient mobile payment options have decreased business transaction costs and are arguably an integral part of the operations of inter-firm commerce and capital exchanges. Besides, they are secure and convenient means through which people with and without access to traditional bank accounts, send, receive, pay, or store money. Use of mobile payments has eliminated the need to use cash, thus offering both speed and convenience (Teo et al., 2015). Standardized interconnectedness and wide acceptance of mobile payment procedures, enables secure transfer of money between devices. Progressively, the variety of ways of paying for goods and services today have shaped the business world and triggered vast transaction freedom.

According to Oxford Business Group (OBG, 2018), the formal retail supply in Kenya is the second largest in Africa and one of the most advanced. In 2017, Kenya's wholesale and retail sector had a gross domestic product contribution of 5.7\%, augmenting its focal role in the country's development 
blueprint- Vision 2030 (OBG, 2018). Kenya's retail sector is largely dominated by local players with few regional firms. However, increasing purchasing power, growing middle class, positive macroeconomic growth, and affordable retail space has attracted international newcomers, increasing the competition of the market niche composed of the urban middle class. In an effort to remain competitive, retailers have diversified their range of products and have resulted in online distribution channels to broaden their market outreach. The latter has been accelerated by the availability of mobile payment platforms both at the point of sale ad remotely.

GSMA (2020) projects that mobile technologies will render a profound economic impact as firms continue to invest in resilient infrastructure. Mobile industry contribution is anticipated to increase to \$184 Billion. Elliot (2019), places the number of global mobile phone subscriptions at 8.3 billion, with 747 million in Sub-Saharan Africa, among which 49.5 million are in Kenya (O'Dea, 2020b). In 2019, the global commerce sales were approximated at \$ 2.32 trillion (Oberlo, 2020), while in Kenya the mobile commerce revenue was reported to be 18.9 \$ billion (O'Dea, 2020a). Without doubt, the mobile payments market will reach critical milestones in the near future as mobile penetration expands and subscriber connections continue to balloon.

The increasingly widespread use of mobile payments has a potential effect on firm performance. Nevertheless, there is contradictory evidence as to whether mobile payment investment by firms yields significant pay backs (Brynjolfsson \& McAfee 2012). Incidentally, prior research has mainly focused on mobile payments from the perspective of consumer adoption and technology aspects (Oliveira et al., 2016. This has led to constricted perspectives, which according to Edwards and Lambert (2007), would be better expounded by exploring the place of moderating variables in order to sufficiently unearth covert underlying relationships.

\section{Research Problem, Questions and Objectives}

With the rapid adoption of mobile payment systems in Kenya that are providing financial inclusion in a country where the financial infrastructure was hitherto undeveloped, it is worth examining if businesses have been able to break even. This is by determining the levels of operating costs, customer uptake, and revenue generation.

Mobile payment is predominantly driven by operational expenditures that include personnel expenditure, huge marketing costs and network agent commissions (Almaza'n \& Vonthron, 2014). During initiation, they require intensive deployment of time and resources intended to acquire and educate potential customers. Consequently, to enhance firm performance, mobile payments must achieve scale through rising transaction values and volumes (Osafo-Kwaako et al., 2018). 
Demographic factors have widely been explored in terms of how they influence adoption of mobile payment technologies (Khan et al., 2015). Consumer attitudes, perceived trust, and mobility affect the adoption of mobile payments. Yeh (2020) examined the technological and social factors that influence customers' adoption of mobile payments. Findings revealed that the quality of service, level of innovation, brand equity, and dynamic public policy are integral connecting variables between intention to use and actual usage behavior as expressed through mobile payment adoption.

This study examines the relationship between mobile payments and firm performance and the consequential implications of user characteristics from a Kenyan perspective. The pertinent questions addressed through this study revolve around how mobile payments relate with firm performance and second whether user characteristics have a moderating impact on the mobile payments and firm performance. A similar study by Jumba and Wepukhulu (2019) targeting supermarkets in Nairobi County is instructive. However, it had a smaller sample size of 66 respondents, was restricted to finance managers, and limited itself to financial performance

Inspired by the need to expound on the role of moderating variables in contextual utilization of mobile payments, this study feeds to the enduring debate on whether and how user characteristics of age, gender, educational level, and employment status, implicate on the relationship subsisting between mobile payments and firm performance. This study therefore adds to the understanding of the benefits accrued by mobile payments, especially in developing countries that have different models from those of advanced economies where most research has hitherto been done.

\section{Literature Review}

Transactions are the heartbeats of business. Today, business leaders are paying more attention to transactional strategy and the attendant response by consumers. Transaction cost theory provides a unique vantage point for examining the nature of transactions concerning emerging technologies (Williamson 1979). Fundamentally, transaction cost theory posits that transactions are expensive and taking into account that diverse modes of transaction in organizations attract different costs. Hence, the theory postulates that there is need to compare the relative costs of various transactions to evaluate the alternative modes that better match the transaction features (Williamson 1979). In every transaction, there are coordination costs of monitoring, controlling, and managing. Thus an organization should adopt a structure that optimizes the economic efficiency while minimizing the costs of exchange. The transaction cost theory's major motivation is informing on how a complex business transaction should be structured and governed to enhance efficiency. 
The use of mobile payment platforms by supermarkets in Kenya is possibly inspired by a desire to craft an organizational response system through a feasible low-cost solution. Purchase of goods and services from supermarkets is a constantly recurring activity, which, if poorly managed, may occasion high costs to firms. In comparison to the conventional payment modes, the mobile payment system presents itself as an efficient alternative that best matches the transaction features associated with Kenyan supermarket shoppers who mainly transact small amounts and have a desire for transactional transparency and affinity for savings. Further, as Suri (2017) notes, mobile payment systems are safer than the cash modes in terms of trust perceptions and low uncertainties. In pursuit of effectiveness and efficiency of transactions, several firms have adopted mobile payment systems. Offhand, mobile payment possesses unique aspects for fulfilling customer needs. Therefore, the contentions presented by transaction cost theory constitute a viable theoretical rationale of why and how mobile payment fits into the modern business world.

\subsection{Mobile payments}

Mobile payments refer to different financial transactions that are carried out through the mobile device. Mobile money services were first launched in Kenya in 2007 and are now available in more than 90 countries with a daily transaction of about $\$ 1.3$ billion from over 866 million registered users (GSMA, 2019). According to the GSMA (2019) report, there are about 163 mobile payments that are active in developing countries with an additional 107 others under development. Those operating in Africa were approximated at 90 while 40 were reported to be in Asia-Pacific and the rest 17 in America. Islam et al., 2016 concludes that there is a positive relationship between mobile payment and a firm's ability to purchase fixed assets a position that compares to Laura (2014) which reported high profits among microenterprises that had adopted mobile payments, a pointer to better firm performance.

Kakwa (2012) asserts that mobile technology has enabled businesses to access new markets. Thus, as a result of the adoption of mobile payments among medium and small enterprises operational costs tend to decline. According to Kirui and Onyuma (2015), mobile money transactions positively enhanced the sales turnover among medium and small enterprises in Nakuru. On a similar premise, Onyango et al., (2014) established that adoption and use of mobile technology enhance the performance of micro and small enterprises.

Based on a private benefit expectation, consumers are willing to pay an imagined price on a given amount of goods. However, sometimes consumers pay less than their actual expectation, which results in utility in the form of consumer surplus. Using the law of diminishing marginal utility, 
mobile payments based on their potential to decrease the price of goods, are bound to increase the consumer surplus (Mahmood, 2016). Hence, at a higher price than the customer expectation (lower consumer surplus), the will to buy would be reduced due to a lesser utility. In effect, mobile payments present an opportunity for consumer surplus creation by reducing on operational costs thereby enhancing a customer's prospects to make savings.

Coombes et al. (1991) posit that firms located in urban areas are usually at a disadvantage of location diseconomies that reduce their profitability. A study by Zouaghi et al. (2017) with a sample size of 3,273 in Spain, observed that geographical location had up to $48.8 \%$ variance on the profitability of a firm. In contrast to the earlier findings, the study concluded that the location of a business in a rural location does not necessarily negatively impact on firm profits.

The budget of a consumer presents the actual purchasing potential that is determined by the money income and prices of the commodities. The ushering of mobile payment presents a consumer with an alternative to the traditional modes of purchase in terms of expenditure on goods and services. Consumers with a budget set opt for goods that are less than or equal to their money income, presenting a budget constraint. However, with alternative payment modes, consumers will prefer an option that offers them more goods at the set budget.

\subsection{Firm Performance}

For a business to remain competitive in the new environment characterized by complexities and uncertainties, it has to develop new products and adopt emerging technology. Such opportunities lie with mobilebased payments. Rapid adoption and use of mobile money systems in developing countries present the respective economies numerous prospects to enhance firm performance. This is on the premise of doing things better, faster, at lower prices, and enhancing continuous firm improvement. Taouab and Issor (2019) define firm performance as the degree to which firm objectives have been met through management, economics, or marketing activities. Their achievement results in firm competitiveness, efficiency, and effectiveness in the overall firm structure and procedures. However, there lacks an absolute consensus among scholars on the operational definition of firm performance. Hence, there are diverse interpretations of the term firm performance. Expectedly, there are a variety of measures of firm performance such as profitability, increased revenue, and uptake of customers. Firm performance is therefore a set of financial and non-financial indicators that points to the level of a firm's accomplishment of its objectives and results.

Measuring firm performance allows the management to monitor performance, report on the firm progress, identify problems and improve on 
the firm's communication strategies Taouab and Issor (2019) recognize firm performance from five distinct perspectives; financial, customer, internal processes, innovation, and learning. A firm's survival and business sustainability are pegged on its ability to control financial resources that determine the organization's returns, revenues and profitability. Harelimana (2018), contends that among the key indicators of firm performance is profitability which again is heavily dependent on income generating activities. Nonetheless, firms should not be obsessed with financial results to the point of ignoring other vital aspects of firm performance. It is also crucial for firms to satisfy their customers by providing quality products and services at favorable prices. A critical aspect under this perspective is acquiring new customers and exploiting new market segments.

Under stiff competition and pressure to increase their profit margins, supermarkets in Kenya are steadily embracing mobile payments systems. One of the probable motivations is to increase the volume of demand and to increase the operational efficiency by minimizing the losses emanating from customer service related delays. Efficiency in customer service may improve the reputation of a firm's logistical capabilities, prompting additional sales and customers. It is therefore presumed that the use of mobile payments by supermarkets, translates into increased revenues, high profits, and additional customers.

\subsection{Demographics}

In analyzing the behavior of customers that leads to the adoption of an innovation, psychology-based theories have evolved to account for the individual behavioral decision. Most of the studies on consumer behavior in the adoption of mobile-based technology have relied on the technology acceptance model. It is conceived that an individual's reaction to the use of new technology affects personal intentions on the use of emerging mobile payments.

Behavioral tendencies and a person's psychological predispositions are key determinants in the adoption of mobile payments (Liu, Luo \& Zhang, 2021). Variables such as perceived usefulness and apparent ease of use determine the willingness of consumers to adopt any given mobile technology. This is in addition to variables such as personal innovativeness and social influence. Social influence is the extent to which a potential user of technology believes that having and using a particular technology is important to others. Perceived usefulness can be understood as the degree to which a person believes the use of a given technology product or service enhances personal performance.

Variables such as expectations of technology performance, expected effort and user attitude go a long way in influencing the behavioral intention 
towards mobile payment (Lee, 2005). Trust and perceived value contribute to customer loyalty and customer satisfaction towards mobile commerce (Lin and Wang, 2006). Perceived value is the trade-off that exists between technology benefits and what the customer forfeits, notably price premium and time to use the innovation. Customer loyalty is greatly affected by satisfaction levels, perceived value, trust, and habit. Amoroso and Hunsinger (2009) determined that factors such as loyalty, convenience, and perceived value influenced customer satisfaction regarding mobile-based applications. Mobile payment adoption and use by consumers is a result of personality traits, psychological factors, social class, membership groups, and cultures. We postulate that consumer characteristics are crucial in predicting consumer use of mobile payment systems in supermarkets. In return, consumer perception of mobile payment, ease of use and value and their trust in it will contribute to the scale of the payment option that will ultimately lead to high firm performance.

Age of mobile payment consumers has been reported to be of significant effect on the behavior of the adoption and use of technology (Okazaki and Mendez, 2013). Mobile-based technology adoption has largely been associated with the younger population as compared to older generations. In a study conducted by Riquelme and Rios (2010), among a sample of about 600 mobile banking users, female respondents inclined more to the ease of use of mobile technology compared to their male counterparts. The perception of others, variously referred to as social norms" was highly perceived among female respondents than the male. The later findings concur with those of Hamza and Shah (2014), that social norms are highly perceived among female students than their male counterparts. Hamza and Shah (2014) reported that perceived ease of use was high among male students than females in Nigeria. However, Wan et al. (2005) concluded that the differences between men and women in internet banking adoption were negligible. Debaillon and Rockwell (2005) also observed a decreasing gender gap in mobile-based technology adoption, leading us to conclude that the findings are inconclusive.

Sulaiman et al. (2007) reported high mobile banking use among individuals who held a master's degree than those who had achieved secondary level education and below. Relatively wealthier customers exhibited a higher tendency to use internet banking. Similarly, individuals with a higher than average income were more likely to use mobile payment than the low earners. Kolodisnky et al. (2004) concluded that an individual's net worth and income are positively related to the adoption of mobile banking, while Lee et al. (2004) contend that income is the most essential determinant of adopting mobile technologies. Consequently, we posit that customer demographics are likely to have a moderating effect between the use of mobile payment and firm performance leading to the following postulation: 
$\mathbf{H}_{0}$ : There is no significant moderating effect of demographic variables on the relationship between mobile payments and firm performance.

\section{Data and Methodology}

Fundamentally, this study features an empirical inquiry that explores the contemporary mobile payment phenomenon in real-life context. The essence is to broaden understanding of the underlying relationship between mobile payments and firm performance while also enriching the theoretical perspectives of mobile use and related consumer characteristics in Kenya. To address relevant study objectives, a descriptive approach alongside the logistic regression model was employed. The descriptive method was deemed acceptable because, by selecting unbiased samples, diverse characteristics of the population would be relied upon to avail a sound platform for analysis.

The study population consisted of 289 supermarkets in Nairobi. This study used a cross-sectional survey to collect data and to systematically integrate all the study elements. According to data available from the Nairobi City County Government, there are about 906 hyper supermarkets and an additional 139 mega supermarkets in Nairobi yielding a study population of 1045 supermarkets that are spread within Nairobi County. Using Krejcie and Morgan (1970), scientific sample size determination formula, a sample size of 282 is deemed representative for a study population of 1045 . However, to ensure diversity and deter chances of bias in the responses, 17 supermarkets from each of the seventeen sub-counties in Nairobi were surveyed totaling up to 289 targeted respondents. This study's independent variable is the mobile payment proxied by usage status of mobile services to make payment. For the dependent variable, proxies, depicted by a binary variable were used.

To analyze the moderating effect of demographics on the relationship between mobile payments and firm performance, the study adopted the following logit regression analysis model.

$\operatorname{Pr}($ Profit $)=\beta_{0}+\beta_{1}[$ Mobile_pay $]+\beta_{2}[$ PrInnv $]+\beta_{3}[$ lnBudget $]+\beta_{4}[$ loct $]+\beta_{5}[$ Lnmr $\mathrm{ktS}]+\beta_{6}[$ Gender $]+\beta_{7}[$ Educl $]+\beta_{8}[$ Emplst $]+\varepsilon_{\mathrm{i}}$

Where:

Profit- the profitability of the firm has increased since adoption of mobile payment services, Yes $=1, \quad 0$ otherwise

Mobile_pay- the customer uses mobile payment services, Yes $=1,0$ otherwise PrInnv - Product innovation has resulted from use of m-payment Services, Yes $=1,0$ otherwise

InBudget - the average monthly shopping budget

Loct- the supermarket is located in Ruaraka $=3$ or Roysambu $=4$ or Mathare $=5$ or Embakasi=9 or Dagoretti=10, 0 otherwise mrktS- logarithm of the number of the supermarket branches 
LnmrktS- logarithm of the number of the supermarket branches

Gender - The gender of the consumer, male $=1,0$ otherwise

Educl - Education level is secondary $=3$ or college $=4$ or university $=5,0$ otherwise

Emplst - Employment status is salary=1 or Self=2 employed, 0 otherwise $\boldsymbol{\varepsilon}_{\text {i- }}$ the error term

\section{Results and Discussion}

A proportion of $74 \%$ of the sampled customers used mobile payment services. Regarding the firm performance, the average revenue generated by the supermarkets in the previous month was Ksh. 14,900,000 with a standard deviation, minimum and maximum of Ksh. 43,200,000, Ksh. 20,000 and Ksh. $400,000,000$ respectively. Moreover, the average customers served by the supermarkets in the previous month was 7208 with a standard deviation of 12656. The minimum customers served was 300 and the maximum customers served was 105000 . Additionally, $80 \%$ of the firms reported an increase in profitability since adoption of M-payment services. Further, the average operating cost incurred by the supermarket in the previous month was Ksh. $9,288,481$ with standard deviation of Ksh. 27,600,000. The minimum operating cost was Ksh. 5,000 and the maximum was Ksh. 270,000,000.

The average age of the consumers was 33.87 years with a standard deviation of 7.92 years. The minimum consumer age was 17 years, and the maximum age was 60 years. A proportion of $48 \%$ of the consumers were male while $93 \%$ of consumers had attained secondary, college and university education levels. Nevertheless, $91 \%$ of the sampled consumers were either salaried or self-employed. $84 \%$ of the consumers affirmed that they would still purchase the items bought despite the prices being higher. The average monthly savings was Ksh. 7,350.84 with a standard deviation of Ksh. 10,471.26. The minimum monthly savings reported was Ksh. 100 while the maximum was Ksh. 80,000. Additionally, 83\% of the supermarkets were in Ruaraka, Roysambu, Mathare, Embakasi and Dagoretti. The average monthly budget was Ksh. 13,223 with standard deviation of Ksh. 21,227.96. Further, the minimum monthly budget was Ksh. 700 while the maximum was Ksh. 225,000 .

Table 1 below presents pairwise correlations among dependent and independent variables. The sample size is 289 supermarkets in Nairobi City County. $*, * *$ and $* * *$ denote significance at the $10 \%, 5 \%$ and $1 \%$ levels respectively. 
Table 1: Pairwise Correlation Analysis

\begin{tabular}{cccccccccc}
\hline & 1 & 2 & 3 & 4 & 5 & 6 & 7 & 8 & 9 \\
\hline 1. Profit & 1 & & & & & & & & \\
2. Mobile_pay & $0.16^{* * *}$ & 1 & & & & & & & \\
3. Gender & $0.12^{* *}$ & 0.02 & 1 & & & & & & \\
4. Educl & 0.03 & 0.03 & 0.04 & 1 & & & & & \\
5. Emplst & 0.02 & -0.05 & 0.08 & 0.06 & 1 & & & & \\
6. MrktS & -0.02 & 0.07 & -0.05 & 0.001 & 0.07 & 1 & & & \\
7. loct & -0.07 & 0.03 & 0.07 & 0.02 & -0.02 & $-0.17^{* * *}$ & 1 & & \\
8. Budget & 0.08 & 0.02 & $0.10^{*}$ & -0.06 & $0.11^{*}$ & 0.01 & 0.01 & 1 & \\
9. PrInnv & -0.05 & -0.04 & 0.04 & -0.01 & 0.08 & -0.08 & -0.02 & -0.04 & 1 \\
\hline
\end{tabular}

The dependent variable, profitability, a proxy for firm performance was found to be positively and significantly correlated with usage status, a proxy for mobile payment. Additionally, a positive and significant correlation was established between firm performance- profitability and consumer characteristics proxied by gender. A positive and significant association was established between gender and the average monthly budget. Further, the employment status was positively and significantly related to the average monthly budget.

From table 2 below, model 1 presents a logit model of mobile paymentMobile_pay on firm performance while model 2 estimates the logit model for moderating effect of demographics on the relationship between mobile payment- Mobile_pay and firm performance. Robust standard errors in parenthesis accounts for heteroscedasticity. $*, * *$ and $* * *$ denote significance at the $10 \%, 5 \%$ and $1 \%$ level respectively.

Table 2: Effect of Demographics on the Relationship between Mobile Payments and Firm Performance

\begin{tabular}{ccccc}
\hline & \multicolumn{2}{c}{ Model 1: Firm Performance (Profit) } & \multicolumn{2}{c}{ Model 2: Firm Performance (Profit) } \\
\cline { 2 - 5 } & Column 1 & Column 2 & Column 3 & Column 4 \\
\cline { 2 - 5 } & Coefficient & Marginal & Coefficient & Marginal Effects \\
& Effects & & \\
\hline Mobile_pay & $0.87^{* * *}$ & $0.15^{* * *}$ & $0.87^{* * *}$ & $0.15^{* * *}$ \\
& $(0.319)$ & $(0.060)$ & $(0.323)$ & $(0.060)$ \\
PrInnv & -0.48 & -0.07 & -0.50 & -0.07 \\
& $(0.526)$ & $(0.063)$ & $(0.529)$ & $(0.061)$ \\
lnBudget & 0.31 & 0.05 & 0.24 & 0.04 \\
& $(0.220)$ & $(0.033)$ & $(0.232)$ & $(0.035)$ \\
Loct & $-0.63 *$ & $-0.08^{*}$ & $-0.67 *$ & $-0.09^{*}$ \\
& $(0.453)$ & $(0.053)$ & $(0.453)$ & $(0.051)$ \\
lnMrktS & -0.19 & -0.03 & -0.17 & -0.03 \\
& $(0.145)$ & $(0.022)$ & $(0.146)$ & $(0.022)$ \\
Gender & & & $0.57 *$ & $0.09 *$ \\
& & & $(0.314)$ & $(0.046)$ \\
Educl & & & 0.15 & 0.02 \\
& & & $(0.561)$ & $(0.092)$ \\
Emplst & & 0.05 & 0.01 \\
\hline
\end{tabular}


$(0.528)$

$-0.67$

(2.070)

No. of

$12.28 * *$
$(2.045)$

287

$-0.91$

287
Observations

$\operatorname{LR} \chi^{2}(5)$

$\operatorname{LR} \chi^{2}(8)$

$15.79 * *$

Our null hypothesis $\left(\mathrm{H}_{0}\right)$ postulates that consumer characteristics have no significant moderating effect on the relationship between mobile payment and firm performance. From model 2 column 4, the marginal effects for Usagest are positive and significant. Therefore, we reject the null hypothesis $\left(\mathrm{H}_{0}\right)$ and conclude that individual demographics have a significant moderating effect on the relationship between mobile payment and firm performance. Hence, the probability of increasing profitability of the firm increases by 15.0 percentage points due to mobile payments. Further, the marginal effects for the gender are positive and significant. Mobile payment usage by male shoppers increases the probability of firm profitability by 9.0 percentage points. Regarding control variables, the marginal effects for location of the firm are negative and significant. Based on the findings, locating the supermarket away from Ruaraka, Roysambu, Mathare, Embakasi and Dagoretti increases probability of the firm by 8.0 percentage points.

Demographic factors are important in that they determine both the use and adoption of mobile payment systems (Garret et al., 2014). It is therefore likely that demographic factors are going to be a major factor in determining the use of mobile payments within business establishments, consequently impacting on firm performance.

Government regulations can implicate financial inclusion, the mobile payment spectrum and ultimately on the overall firm performance. The Kenya Finance Act enacted in 2021, increased excise duty on mobile related services. Heavy taxes and stringent regulations may affect a firm's ability to grow or maintain a customer base, develop the necessary infrastructure and capability as well as inform on the product range that can be offered through mobile payments. Even as the regulators seek to enhance the gross domestic production and financial inclusion within their economies. However, such interests should consider the sustainability of mobile payment systems by integrating fiscal strategies with prevailing business environment realities. For instance, it is worthwhile for Kenyan regulators to recognize that while affordable tariff structures may reduce firm profit margins, they could broaden the customer base leading to greater returns in the long term. 


\section{Conclusions and Recommendations}

This study extends the scholarship on the relationship between mobile payment, demographics and firm performance by addressing pertinent gaps within the current body of knowledge. The findings are significant towards developing the general understanding of the mobile payment models that have been deployed in retail enterprises and could offer useful insights to other entities.

The study findings offer a novel perspective, more so that relationships between mobile payments and firm performance could be moderated by demographic variables. For practitioners namely, mobile network operators, investors, and firms, these findings are critical in informing the development of future mobile payment models and structuring marketing campaigns for consumer uptake.

Globally, mobile payment systems are facilitating financial inclusion and offering businesses an opportunity for growth. Mobile payment services are popular in developing countries and emerging markets since they avail cheap financial services that are easily accessible. However, during the early deployment of mobile payment systems, firms may encounter meager earnings as a result of high initial outlay and operating costs typical at the deployment stages. For mobile payment systems to generate profits, revenue generation has to exceed both operational and commercial costs. This is possible with high volumes of sales underpinned by a broad consumer base whose individual transactions should attract low costs.

Firms need to focus on investing in the drivers of mobile payment as they continuously explore other innovative services and products that can be derived within the system. Imperatively, businesses in Kenya need to foster mobile payment use, by analyzing and exploiting user demographics. This study offers better insights for businesses to tailor mobile payment products that are suitable to different consumers, hence increasing the uptake of mobile payments that may translate into better firm performance by realizing the necessary threshold.

The findings of this study should be construed in light of some limitations that could inform future research initiatives. Our research predominantly focused on operations within the realm of supermarkets. Certainly, there are many other types of businesses that are making use of mobile payments. Future studies could explore the state of affairs in other types of businesses. Further, our study was carried within Nairobi city. Most of the supermarkets in the survey were basically in urban areas. Further exploration can be focused on firms that are within rural setups, that may not have the advantages of concentration of specialization such as information and technology skills. More so, financial intermediation is costly due to the spread of users over a large geographical location and the financial transactions are 
small and individual incomes are to a great extent unstable. Future studies could also explore the influence of financial regulations on mobile payments and firm performance. Lastly, an in-depth analysis of the mobile-payment and firm-specific commercial and operating costs would greatly enhance the overall understanding of the mobile technologies market growth and deployment stages. Overall, this work offers a solid launching pad towards a more elaborate understanding of how mobile payments relate to firm performance in the context of consumer demographics.

\section{References:}

1. Almaza'n, M., \& Vonthron, N. (2014). Mobile Money for the Unbanked Mobile money profitability: A digital ecosystem to drive healthy margins. Accessed on July 1 2020. Available: https://www.gsma.com/mobilefordevelopment/wpcontent/uploads/2015/11/2014_Mobile-money-profitability-A-digitalecosystem-to-drive-healthy-margins.pdf

2. Amoroso, D. L., \& Hunsinger, D. S. (2009). Understanding consumers' acceptance of online purchasing. Journal of Information Technology Management, 100 (1) 15-41.

3. Bandura, R., \& Ramanujam, S. R., (2021). Developing inclusive digital payment systems. Center for Strategic \&International Studies. Available: https://www.csis.org/analysis/developing-inclusivedigital-payment-systems

4. Brynjolfsson, E., \& McAfee, A. (2012). Big Data: The Management Revolution. Available: http:/hbr.org/2012/10/big-data-themanagement-revolution/ar

5. Coombes, M., Storey, D., Watson, R., \& Wynarczyk, P. (1991). The Influence of Location upon Profitability and Employment Change in Small Companies. Urban Studies, 28(5), 723-734.

6. DeBaillon, L., \& Rockwell, P. (2005). Gender and student-status differences in cellular telephone use. International Journal of Mobile Communications, 3(1), 82.

7. Demombynes, G., \& Thegeya, A. (2012). 'Kenya's Mobile Revolution and the Promise of Mobile Savings' (Policy Research Working Paper No WPS5988.). World Bank.

8. Edwards, J. R., \& Lambert, L. S. (2007). Methods for integrating moderation and mediation: A general analytical framework using moderated path analysis. Psychological Methods, 12, 1-22.

9. Elliott, R. (2019). Mobile Phone Penetration Throughout Sub-Saharan Africa - GeoPoll. Retrieved from https://www.geopoll.com/blog/mobile-phone-penetration-africa/ 
10. Garrett, J. L., $\quad$ Rodermund, R., Anderson, N., Berkowitz, S., ～\& Robb, C. A. (2014). Adoption of Mobile Payment Technology by Consumers. Family and Consumer Sciences Research Journal, 42 (2), 358-368.

11. GSMA (2020). "The mobile Economy Sub-Saharan Africa 2020." Accessed on $6^{\text {th }} \quad$ July 2021. Available:https://www.gsma.com/mobileeconomy/wpcontent/uploads /2020/09/GSMA_MobileEconomy2020_SSA_Eng.pdf

12. GSMA (2019). "2018 State of the Industry Report on Mobile Money". Retrieved from https://www.gsma.com/mobilefordevelopment/resources/2018-stateof-the-industry-report-on-mobilemoney/

13. Government of Kenya (2021). Finance Act, 2021. Government Printer.

14. Hamza, A., \& Shah, A. (2014). Gender and mobile payment system adoption among students of tertiary institutions in Nigeria. New Media and Mass Communication. doi:10.7176/nmmc/89-02

15. Harelimana, J. B. (2018). Impact of Mobile Banking on Financial Performance of Unguka Microfinance Bank Ltd, Rwanda. Journal of Harmonized Research in Management, 4(1), 26.

16. Islam, A., Muzi, S., \& Meza, J. L. (2016). Does Mobile Money Use Increase Firms' Investment? (7890) Retrieved from World Bank Group website: http://documents1.worldbank.org/curated/en/491931479153921241/p df/WPS7890.pdf

17. Jumba, J., \& Wepukhulu, J. (2019). Effect of Cashless Payments on the Financial Performance of Supermarkets in Nairobi County. International Journal of Academic Research in Business and Social Sciences, 9(3). doi:10.6007/ijarbss/v9-i3/5803

18. Kakwa, P. A. (2012). Mobile phone usage by micro and small scale enterprises in Semi-Rural Ghana. International Review of Management and Marketing 2(3): 156-164, 2(3), 156-164.

19. Khan, H. U., Musa, A., \& Alshare, K. (2015). Factors Influence Consumers' Adoption of Mobile Payment Devices in Qatar. International Journal of Mobile Communications, 13(4), 670-688.

20. Kirui, K. R., \& Onyuma, S. O. (2015). Role of Mobile Money Transactions on Revenue of Microbusiness in Kenya. European Journal of Business and Management, 7(36), 63-67.

21. Kolodinsky, J. M., Hogarth, J. M., \& Hilgert, M. A. (2004). The adoption of electronic banking technologies by US consumers. International Journal of Bank Marketing, 22(4), 238-259.

22. Krejcie, R. V., \& Morgan, D. W. (1970). Determining Sample Size for Research Activities. Educational and Psychological Measurement. 
23. Laura, F. I. (2014). Impact of mobile money usage on microenterprise evidence from Zambia.

24. Lee, E., Eastwood, D. B., \& Lee, J. (2004). A sample selection model of consumer adoption of computer banking. Journal of Financial Services Research, 26 (3), 263-275.

25. Lee, T. (2005). The impact of perceptions of interactivity on customer trust and transaction intentions in mobile commerce. Journal of Electronic Commerce Research, 6 (3), 165-180.

26. Lin, H., \& Wang, Y. (2006). An examination of the determinants of customer loyalty in mobile commerce contexts. Information \& Management, 43 (3), 271-282.

27. Liu, Y., Luo, J. \& Zhang, L. (2021). The effects of mobile payments on consumer behavior. Journal of Consumer Behavior, 20, 512-520.

28. Lu, J., Yao, J. E., \& Yu, C. (2005). Personal innovativeness, social influences and adoption of wireless Internet services via mobile technology. The Journal of Strategic Information Systems, 14 (3), 245268.

29. Mahmood, I. P. (2016). The Palgrave Encyclopedia of Strategic Management. London: Palgrave Macmillan.

30. Monsuwe, T. P., Dellaert, B.G., \& Ruyter, K.D (2004). What drives consumers to shop online? A literature reiew. International Journal of Service Industry Management. 15 (1) 102-121.

31. Oberlo. (2020). Mobile Commerce Sales in 2020. Retrieved from https://www.oberlo.com/statistics/mobile-commerce-sales

32. OBG. (2020). Optimism grows as Kenyan retailers adapt to change | Kenya 2018 | Oxford Business Group. Retrieved from https://oxfordbusinessgroup.com/overview/new-and-improvedoptimism-grows-retailers-adapt-challenges

33. O'Dea, S. (2020a). Number of cellular subscriptions Kenya 20002018.

Retrieved

from http://www.statista.com/statistics/498385/number-of-mobile-cellularsubscriptions-in-kenya

34. O'Dea, S. (2020b). Mobile commerce transaction value by quarter in Kenya 2018-2019 | Statista. Retrieved from https://www.statista.com/statistics/1067531/quarterly-mobilecommerce-transaction-value-in-kenya/

35. Okazaki, S., \& Mendez, F. (2013). Exploring convenience in mobile commerce: Moderating effects of gender. Computers in Human Behavior, 29(3), 1234-1242.

36. Okereke, D. (2017). Factors Driving Mobile Payment Adoption: Benefits, Challenges \& Opportunities (Unpublished doctoral dissertation). University of South Wales, Newport. 
37. Oliveira, T., Thomas, M., Baptista, G., \& Campos, F. (2016). Mobile payment: Understanding the determinants of customer adoption and intention to recommend the technology. Computers in Human Behavior, 61, 404-414.

38. Onyango, R., Ongus, I. W., Awour, M. F., \& Nyamboga, C. (2014). Impact of adoption and use of mobile phone technology on the performance of micro and small enterprises in Kisii Municipality Kenya. World Journal of Computer Application and Technology, 2(2), 34-42.

39. Osafo-Kwaako, P., Zouaoui, Y., Singer, M., \& White, O. (2018). Mobile money in emerging markets:The business case for financial inclusion. Retrieved from McKinsey \& Company website: https://www.mckinsey.com

40. Riquelme, H. E., \& Rios, R. E. (2010). The moderating effect of gender in the adoption of mobile banking. International Journal of Bank Marketing, 28(5), 328-341.

41. Sulaiman, A., Jaafar, N. I., \& Mohezar, S. (2007). An overview of mobile banking adoption among the urban community. International Journal of Mobile Communications, 5(2), 157-168.

42. Suri, T. (2017). Mobile Money. The Annual Review of Economics, 9 , 497-520.

43. Taouab, O., \& Issor, Z. (2019). Firm Performance: Definition and Measurement Models. European Scientific Journal ESJ, 15(1).

44. Teo, A., Tan, G. W., Ooi, K., Hew, T., \& Yew, K. (2015). The effects of convenience and speed in m-payment. Industrial Management \& Data Systems, 115 (2), 311-331.

45. Wan, W. W., Luk, C., \& Chow, C. W. (2005). Customers' adoption of banking channels in Hong Kong. International Journal of Bank Marketing, 23(3), 255-272.

46. Williamson, O. (1979). Transaction-cost economics: The governance of contractual relations. Journal of Law and Economics, 22, 233-261.

47. Yeh, H. (2020). Factors in the Ecosystem of Mobile Payment Affecting its Use: From the Customers' Perspective in Taiwan. Journal of theoretical and applied electronic commerce research, 15(1), 5779.

48. Zouaghi, F., Sanchez-Garcia, M., \& Hirsch, S. (2017). What drives firm profitability? A multilevel approach to the Spanish agri-food sector. Spanish Journal of Agricultural Research, 15 (3), 90-117. 